\title{
Agency and intentionality-dependent experiences of moral emotions
}

Bland, A. R.1,2*, Schei, T.3, Roiser, J. P.4, Mehta, M. A.5, Zahn, R.5, Seara-Cardoso, A.6,7, Viding, E.6, Sahakian, B. J.3,8, Robbins, T. W.8,9 and Elliott, R. ${ }^{1}$

\section{*corresponding author}

1Neuroscience and Psychiatry Unit, University of Manchester, UK

2Department of Psychology, Manchester Metropolitan University, Manchester, UK

${ }^{3}$ Department of Psychiatry, University of Cambridge, UK

${ }^{4}$ Institute of Cognitive Neuroscience, University College London, UK

${ }^{5}$ Centre for affective disorders, Institute of Psychiatry, Psychology and Neuroscience, Kings College London, UK

6Psychology and Language Sciences, University College London, UK

${ }^{7}$ School of Psychology, University of Minho, Portugal

${ }^{8}$ Behavioural and Clinical Neuroscience Institute, University of Cambridge, UK

${ }^{9}$ Department of Psychology, University of Cambridge, UK

\begin{abstract}
Moral emotions are thought to influence moral behaviour by providing a driving force to do good and to avoid doing bad. In this study we examined moral emotions; specifically, guilt, shame, annoyance and feeling "bad" from two different perspectives in a moral scenario; the agent and the victim whilst manipulating the intentionality of the harm; intentional and unintentional. Two hundred participants completed a moral emotions task, which utilised cartoons to depict everyday moral scenarios. As expected, we found that self-blaming emotions such as shame and guilt were much more frequent when taking on the perspective of the agent whilst annoyance was more frequent from the victim perspective. Feeling bad, however, was not agency-specific. Notably, when the harm was intentional, we observed significantly greater shame ratings from the perspective of the agent compared to when the harm was unintentional. In addition, we also found clear gender differences and further observed correlations between moral emotions and personality variables such as psychoticism and neuroticism.
\end{abstract}




\section{Introduction}

We regularly face scenarios in which judgements have to be made as to whether an action is right or wrong, ranging from extremes such as criminal acts, to more trivial questions of telling a "white lie". In addition to reasoning in moral judgements, it is recognised that emotionally driven aspects of the judgement procedure are critically important. For instance, offensive but harmless actions, such as washing the bathroom with the national flag or eating a dead family pet provokes strong moral condemnation, but individuals are unable to justify their disapproval beyond stating it as wrong (Haidt et al., 1993). These moral emotions are thought to influence the link between moral standards and moral behaviour (Tangney et al., 2011) and provide a driving force to do good and to avoid doing bad (Kroll and Egan, 2004).

It has been suggested that some moral dilemmas elicit emotional responses more than others, and that this affects moral judgments (Greene et al., 2001). There is also evidence showing that changing the emotional state of individuals influences their moral judgements. For example, participants who watched a happy movie in comparison to a neutral movie were more likely to choose the morally 'appropriate' choice in a moral dilemma by sacrificing an individual for the greater good (Valdesolo and DeSteno, 2006), whereas in a separate study eliciting anger led participants to condemn justice violations more harshly (Horberg et al., 2011). The notion that emotions influence moral judgements is also consistent with the results of neuroimaging studies, which have shown activation of brain regions typically associated with emotion when participants are faced with moral dilemmas (Greene et al., 2001), everyday moral transgressions (Seara-Cardoso, et al. 2016) or pictures with moral content (Moll et al., 2002). Moral emotional experience has been demonstrated to be relevant to depression with patients showing agencyselective neural changes in moral emotional networks (Green et al. 2012; Zahn et al. 2015). 
'Moral emotions' refer to emotions that are associated with social interactions. They differ from basic emotions by encompassing the interests of persons other than oneself (Haidt, 2003; Moll et al., 2002). Moral emotions change depending on whether we direct blame towards ourselves (e.g. guilt, shame) or others (e.g. moral anger) (Zahn et al., 2011; Zahn, et al., 2020). Shame and guilt are defined as "self-conscious emotions" but have clear differences (Tangney et al., 2007). Shame is viewed as the more "public" emotion (arising from public exposure and disapproval) leading to a negative evaluation of the self, whereas guilt refers to a more "private" experience associated with internally-generated pangs of conscience leading to the negative evaluation of a specific behaviour (Tangney et al., 2011). By contrast, moral anger is associated with violations of the rights of individuals (Russell and Giner-Sorolla, 2013) and has been previously associated with attributions of intentionality and blame (Alicke, 2000; Tetlock et al., 2007).

Moral emotions differ depending on a person's perspective of the moral scenario, i.e. agent, victim, observer and whether the act was intentional (Zahn et al., 2012; Buon et al., 2016). For instance, guilt or shame result from negative outcomes attributed to one's self, and moral anger results from negative events attributed to illegitimate acts of others (Lawler and Thye, 1999). Further, intentionality of the harm is an important factor in generating moral emotions. Whilst anger is often experienced with intentional moral scenarios, unintentional harms are believed to elicit compassion (Petersen, 2010).

Moral emotional experience also differs depending on individual differences such as age, gender and personality. For instance, children and adolescents through to adults have reportedly different experiences of shame and guilt, which have differential consequences on behaviour (Tangney, et al., 2007). Research also suggests that women experience higher self-conscious moral emotions such as guilt and shame compared to men (Else-Quest et al., 2012). In addition, moral emotions are liked with personality with shame and guilt proneness correlate with neuroticism, agreeableness and extraversion (Abe, 2004; Einstein and Lanning, 1998; Harder and 
Greenwald, 1999). Finally, although the development of moral reasoning is often linked to intelligence, moral emotions do not rely on logic and analytical skills (Malti et al., 2013; Malti and Buchmann, 2010). Nevertheless, the developmental emergence of moral emotions is largely dependent on moral cognitive ability (Dentici and Pagnin, 1992; Malti and Latzko, 2010).

In the present study we used a novel moral emotions task focusing on two different perspectives in a moral scenario; the agent (i.e. the person who committed the act in the moral scenario) and the victim (the person who experiences the consequences of that act) whilst manipulating the intentionality of the harm caused in the moral scenario; intentional (the agent intended to cause harm) or unintentional (the harm was an accident). The most commonly explored moral emotions are guilt, shame, embarrassment and pride (Tangney and Fischer, 1995), however we chose to focus on the negative "self-conscious emotions"; guilt and shame. Whilst pride is a positive moral emotion, embarrassment although not distinct from shame, is often difficult for people to separate (Crozier, 2014). We also chose to include "annoyance" a negative but not selfconscious non-moral emotion and "feeling bad", a more general feeling for when people cannot specify a distinct emotion. Our objective was to explore individuals' feelings of guilt, shame, annoyance and feeling bad when taking on the perspective of each role, and further establish any effects of gender, age or personality traits. We hypothesised that shame and guilt would be greater when taking on the role of the agent compared to the victim and that these moral emotions heightened when the harm was intentional. We further hypothesised a distinction between guilt and shame based on the perspective with agents feeling more guilt and victims feeling more shame. 


\section{Materials and Methods}

\section{Participants}

We recruited two hundred healthy volunteers (as described previously in Bland et al., 2016ㄷ). Inclusion criteria were as follows: 18-50 years old, no previous or current psychiatric disorders,, no significant head injury, no current use of medication known to affect mood or cognition, no first degree relatives suffering from any psychiatric disorders, smoking less than 5 cigarettes per day, drinking less than the UK government guidelines for weekly alcohol intake and fluent in English. The Brief Symptom Inventory (Derogatis and Melisaratos, 1983) and the Mini International Neuropsychiatric Interview (Sheehan et al., 1998) were administered to participants who were excluded if they met the criteria for any psychiatric diagnosis. This study was approved by Research Ethics Committees at the University of Manchester and the University of Cambridge.. Participants were reimbursed for their time and travel expenses.

Data from 199 participants were analysed due to one participant's data failing to download. Participants' mean age was 26.66 years $(\mathrm{SD}=9.81)$ and a mean Wechsler Test of Adult Reading (WTAR) score of $112.18(\mathrm{SD}=6.29)$. The sample consisted of 99 male and 100 female participants, half of whom were educated to degree level.

\section{Experimental procedure}

Prior to the visit, participants completed five questionnaires online: Big Five Personality Inventory (John et al., 1991), Eysenck Personality Inventory (EPQ: Eysenck and Eysenck, 1991), the Barratt Impulsivity Scale (BIS-11: Patton et al., 1995), the UPPS-P Impulsive Behaviour Scale (Whiteside and Lynam, 2003) and the trait section of the State-Trait Anxiety Inventory (STAI: Spielberger et al., 1970). On the day participants further completed two current mood state questionnaires: Profile of Mood States (POMS: Shacham, 1983) and the state section of the STAI

\footnotetext{
1 The present paper presents reanalysed material distinct from Bland et al (2016)
} 
(Spielberger et al., 1970). Wechsler Test of Adult Reading (Wechsler, 2008) was used to estimate participants' IQ. Participants were seated in a in a quiet testing room and completed the task on a touchscreen laptop (Dell XT3) using PsychoPy software (Peirce, 2007). The moral emotions task was administered as part of the EMOTICOM neuropsychological test battery (Bland, et al 2016).

\section{Moral Emotions Task}

The task uses cartoons to depict 14 everyday moral scenarios which were partially adapted from previous approaches that used text based vignettes to convey the scenarios (SearaCardoso et al., 2016). Half of the scenarios depicted intentional harms (e.g. the agent blames the victim for the agent's breakage) and the other half unintentional (e.g. the agent loses the victim's dog). Participants were asked to imagine how they would feel in the situation and rate the following emotions: guilt, shame and annoyance on a 6-point scale ranging from "not at all" to "extremely" and feeling bad on a scale of 6-point scale ranging from "bad" to "good". Participants were shown each scenario twice, once as the victim and once as the agent of the harm. The task lasted approximately 13 minutes (Figure 1).

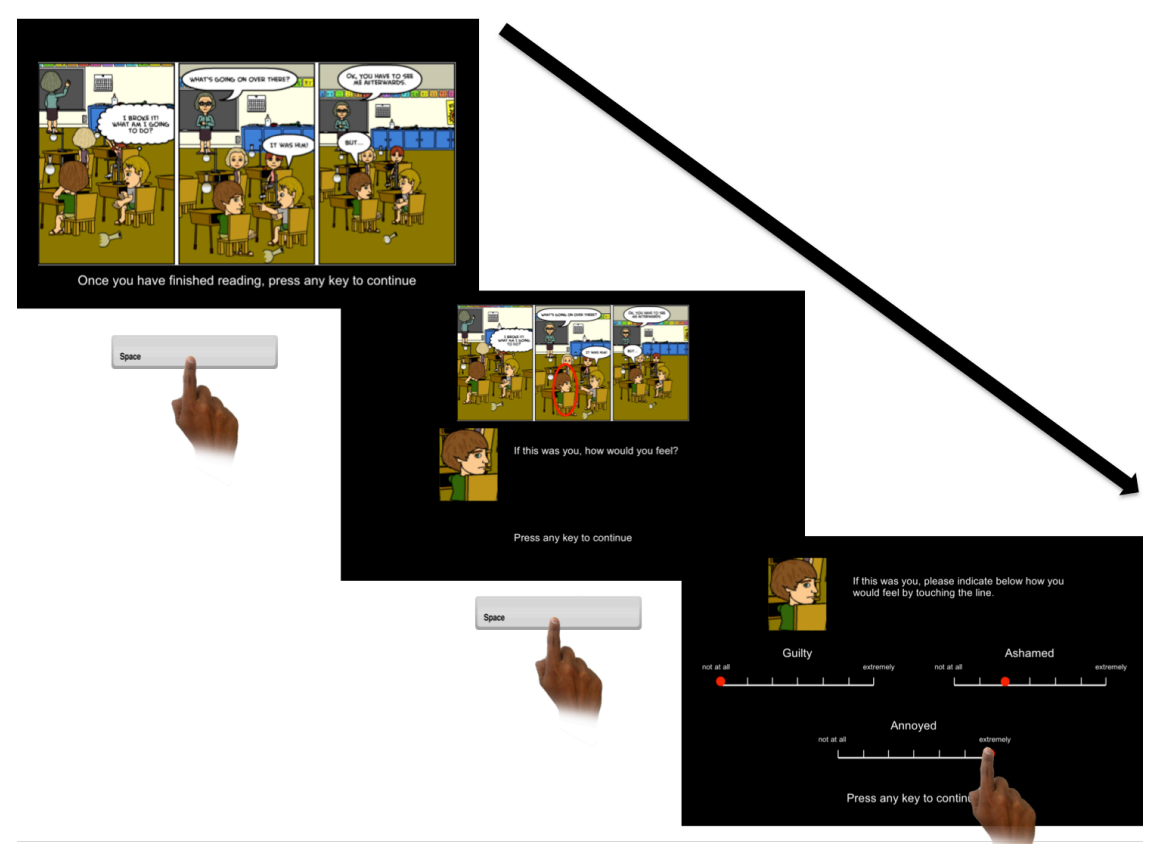

Figure 1: Figure to show the moral emotions task 


\section{Analysis}

All statistics were computed with SPSS statistical software (IBM, Version 20.0). Post-hoc analyses were performed for significant main effects using Bonferroni correction. Ratings from the moral emotions task were normalised from the 6-point likert scale to values ranging $0-1$. Bad ratings were reversed scored. Data were then entered into a 4(moral emotion: guilt vs shame vs annoyance vs bad) x2(agency: victim vs agent) x2(intentionality: intentional vs unintentional) repeated measures General Linear Model (GLM). Gender was entered as a between subjects factor. A violation of the assumption of sphericity was indicated by Mauchly's test $\left[\chi^{2}(5)=43.10\right]$, therefore the Greenhouse-Geisser correction was reported for the repeated measures ANOVA. The assumption of homogeneity of variance for t-tests were assessed using the Levene statistic which showed one significant violation $(\mathrm{p}<0.05)$ for agent guilt and was therefore degrees of freedom were adjusted accordingly.

Two-tailed Pearson's correlations were used to relate performance on the tasks to personality measures in order to assess how ratings are associated with other psychologically relevant characteristics, as well as age, IQ and years in education. The statistical significance of all correlations were corrected for multiple comparisons $(0.05 / \mathrm{n} ; \mathrm{n}=$ number of task variables $)$ and subsequently significant levels set to $p<0.003$. Cohen's $d$ effect size was calculated as Cohen's $d=\left(\mathrm{M}_{2}-\mathrm{M}_{1}\right) / \mathrm{SD}$ difference. With 199 participants we had $90 \%$ power to detect differences between conditions of $d=0.23$ at $p=0.05$ (two-tailed). Split-half reliability was computed using the Spearman-Brown formula (Wilson, 2010) after randomly splitting items in each condition into parallel forms. All Split-half reliability coefficients were greater than 80 (ranging from 0.82 to 0.90 ). 


\section{Results}

There was a significant 2-way agency x emotion interaction $[F(2.31,454.92)=104.09, p<0.001$, $\eta p^{2}=0.35$ )] (Figure 2). Post-hoc analyses revealed significant effects of emotion for both the $\left.\operatorname{victim}\left[F(1.86,366.94)=1920.68, p<0.001, \eta p^{2}=0.91\right)\right]$ and agent conditions $[F(1.67,329.21)=$ 634.90, $\left.\left.p<0.001, \eta_{p}{ }^{2}=0.76\right)\right]$. When participants took on the perspective of the victim they felt significantly more shame compared to guilt $[t(198)=14.29, p<0.001, d=0.10]$ and significantly more annoyance compared to both guilt $[t(198)=50.00, p<0.001, d=3.54]$ and shame $[t(198)$ $=41.14, p<0.001, d=2.92]$. However, when the participant took on the perspective of the agent they felt significantly more guilt compared to shame $[t(198)=12.39, p<0.001, d=0.88]$ and significantly less annoyance compared to both guilt $[t(198)=28.45, p<0.001, d=1.28]$ and shame $[t(198)=24.08, p<0.001, d=1.70]$. Feeling "bad" ratings were not significantly different from ratings of annoyance when taking on the role of the victim $[p=0.20]$ and not significantly different from guilt ratings when taking on the role of the agent $[p=0.41]$.

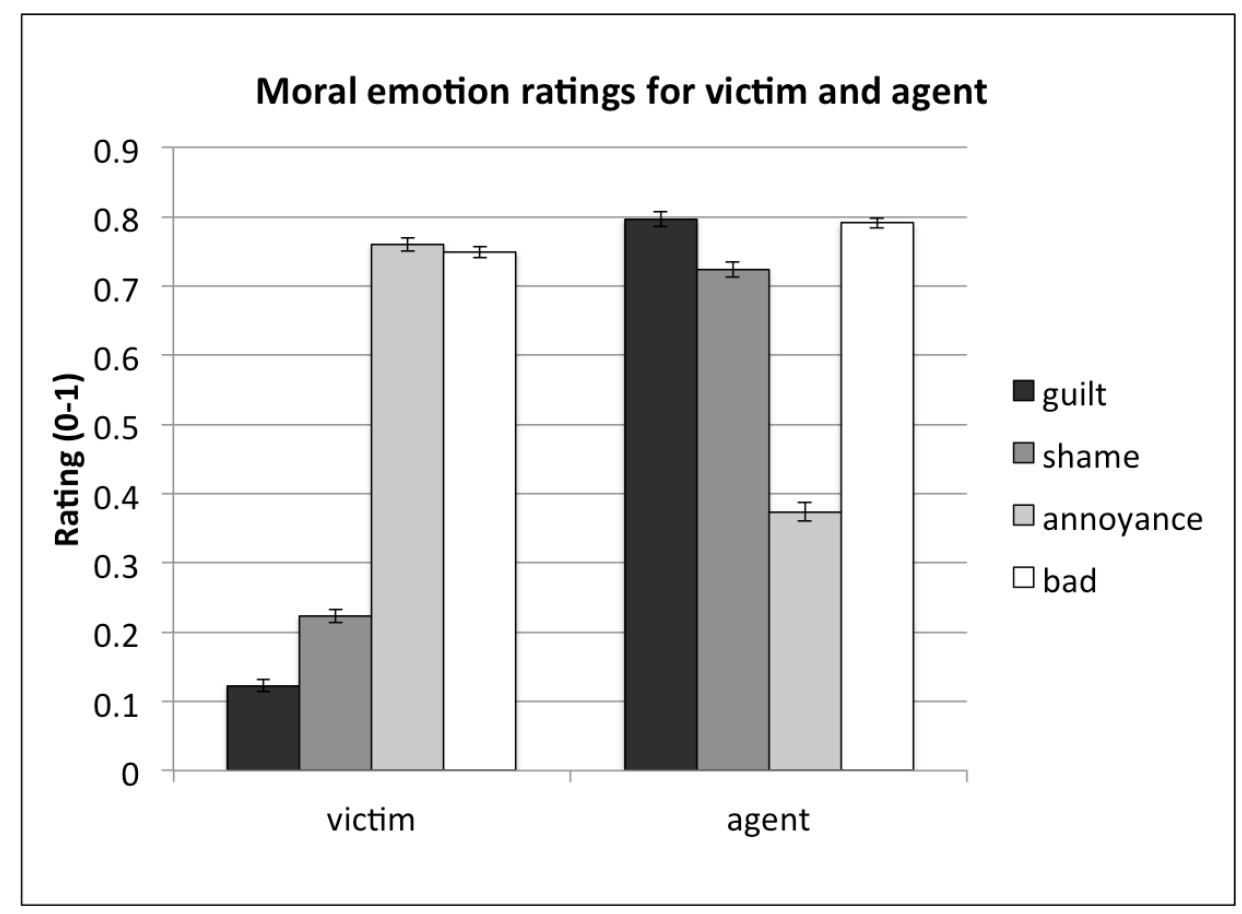

Figure 2: Bar chart with standard error bars to show ratings for guilt, shame, annoyance and bad from both the victim and agent perspective 


\section{Intentionality}

When considering the role of intentionality there was a significant 3-way interaction of agency $\mathrm{x}$ emotion $\mathrm{x}$ intentionality $\left.\left[F(2.34,461.16)=22.0, p<0.001, \eta p^{2}=0.10\right)\right]$. Post-hoc analyses revealed significant effects of emotion $\mathrm{x}$ intentionality for both the victim $[F(2.40,473.24)=$ $\left.\left.60.91, p<0.001, \eta p^{2}=0.24\right)\right]$ and agent $\left.\left[F(1.89,372.00)=52.49, p<0.001, \eta p^{2}=0.21\right)\right]$ conditions. When participants took on the perspective of the victim they showed significantly greater ratings of moral emotions when the harm was intentional compared to unintentional; guilt $[t(198)=3.93, p<0.001, d=2.78]$, shame $[t(198)=15.70, p<0.001, d=1.11]$, annoyance $[t(198)$ $=6.86, p<0.001, d=0.49]$, and bad $[t(198)=9.45, p<0.001, d=0.67]$. However, when the participant took on the perspective of the agent there was no significant difference of intentionality in guilt [ $p=0.39]$ or bad ratings [ $p=0.31]$, but participants expressed greater shame $[t(198)=2.74, p<0.01, d=0.19]$ and less annoyance $[t(198)=-7.80, p<0.001, d=0.55]$ for intentional harms.

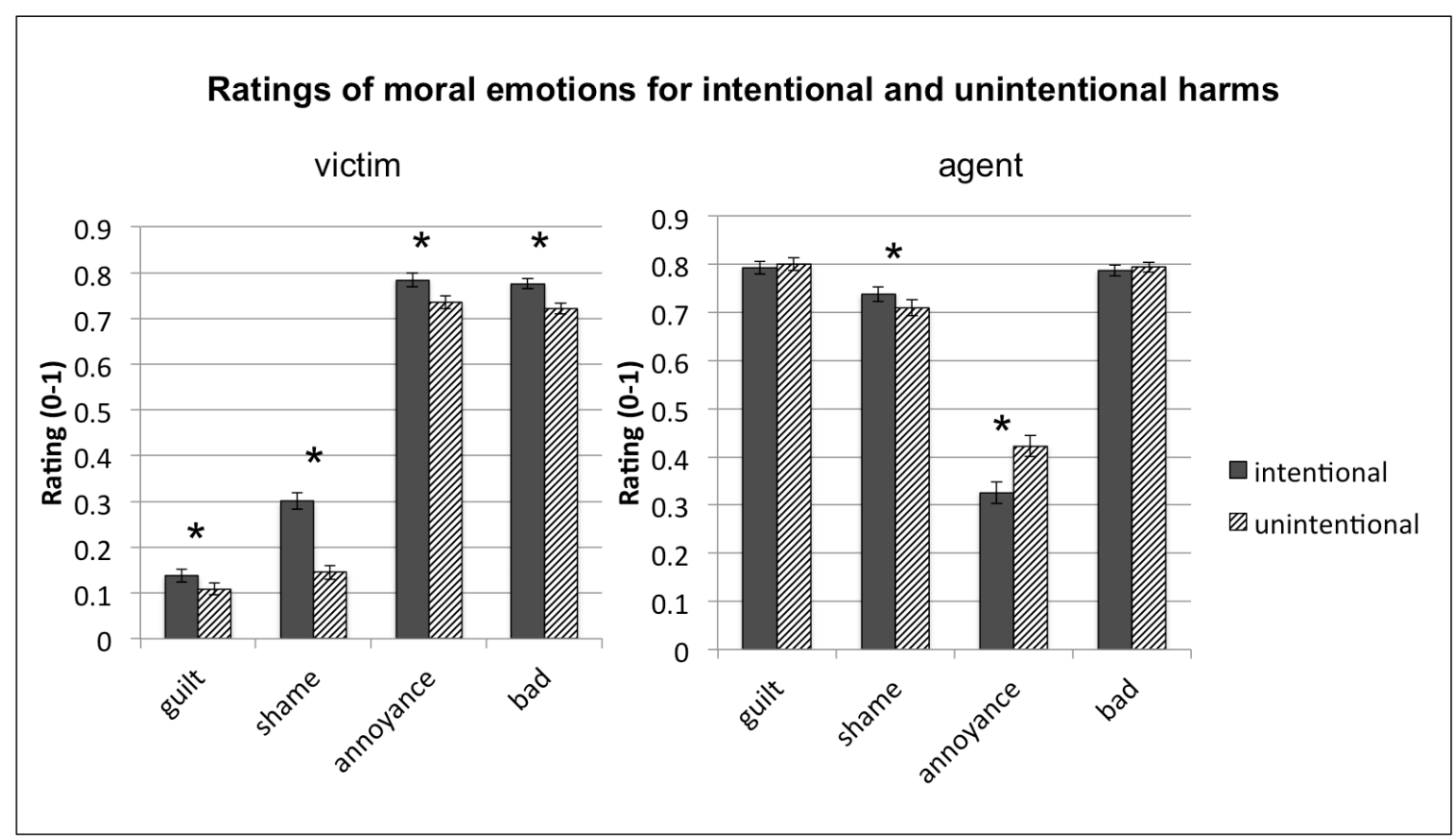

Figure 3: Bar chart with standard error bars to show ratings for guilt, shame, annoyance and bad separated by intentionality from both the victim and agent perspective 


\section{Effects of gender, age, IQ and personality variables}

When considering the role of gender there was a significant 4-way gender $\mathrm{x}$ agent $\mathrm{x}$ intentionality $\mathrm{x}$ emotion interaction $\left.\left[F(2.34,461.16)=5.83, p<0.001, \eta p^{2}=0.03\right)\right]$. Post-hoc analyses revealed a significant gender $\mathrm{x}$ emotion $\mathrm{x}$ intention interaction when taking on the role of agent $\left.\left[F(1.89,372.00)=7.76, p<0.001, \eta p^{2}=0.04\right)\right]$. Females, when identifying as the agent, showed significantly greater guilt $[t(174.89)=4.02, p<0.001, d=0.10]$ and shame $[t(197)=$ $3.15, p<0.01, d=0.12]$ regardless of intentionality. When taking on the role of the victim, the significant gender $\mathrm{x}$ emotion $\mathrm{x}$ intention interaction did not survive Bonferroni correction for multiple comparisons $\left.\left[F(2.40,473.24)=3.27, p=0.04, \eta p^{2}=0.02\right)\right]$ and further post hoc tests showed that females did not differ from males in guilt $[p=0.60]$, shame $[p=0.36]$, annoyance $[p$ $=0.20]$ and bad ratings $[p=0.28]$, regardless of intentionality.

\section{Moral emotion agent ratings in females and males}

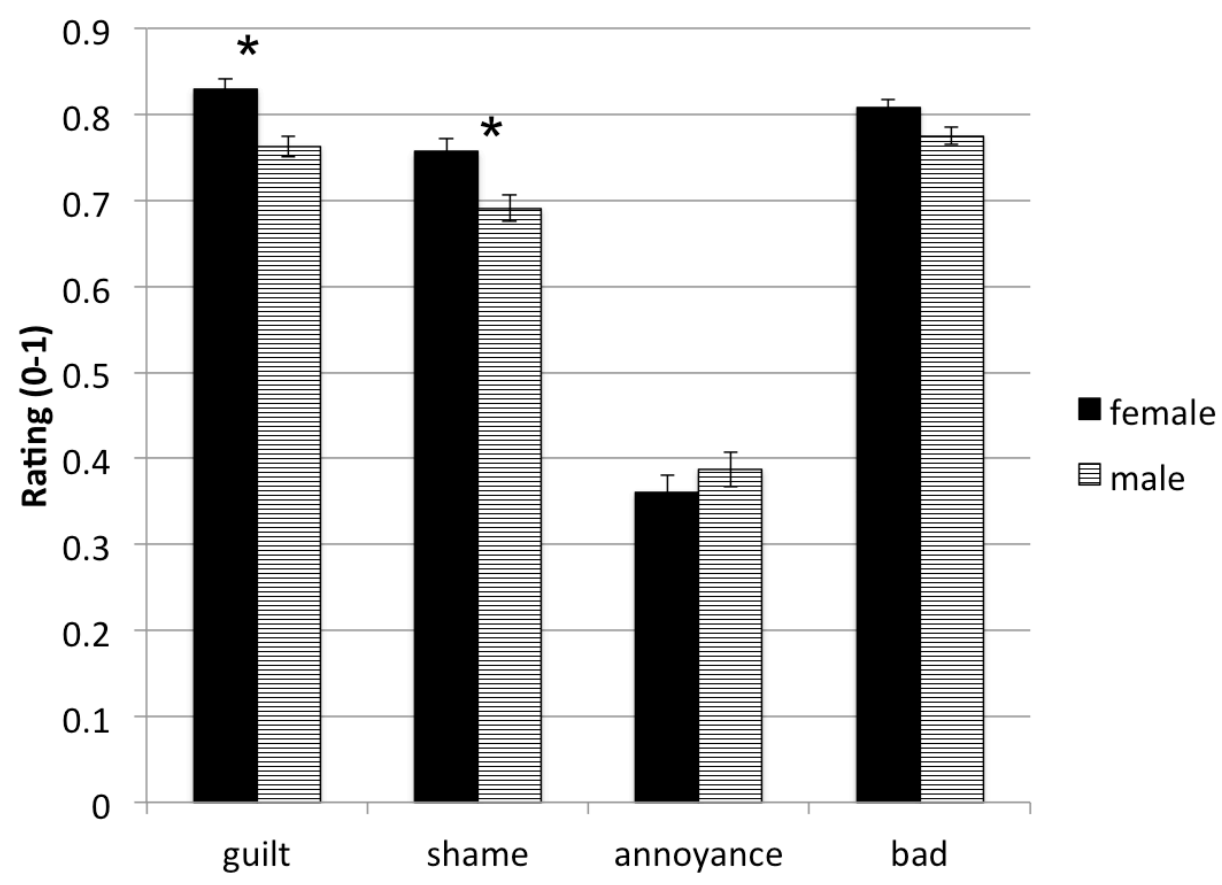

Figure 4: Bar chart with standard error bars to show ratings for guilt, shame, annoyance and bad separated by gender 
We also investigated the relationship between moral emotions, age and IQ. We found that older participants felt more annoyance $[r=0.23, p<0.001]$, however, we observed no significant correlations with IQ [all $p>0.05$ ].

We found that EPQ Psychoticism was significantly correlated with ratings of agent guilt $[r=-$ $0.34, p<0.001]$, agent shame $[r=-0.37, p<0.001]$ and agent bad $[r=-0.33, p<0.001]$ regardless of intentionality. EPQ-Psychoticism however did not significantly correlate with moral emotions associated with taking the role of the victim [all $p>0.10]$. We also observed that EPQNeuroticism positively correlated with agent shame regardless of intentionality $[r=0.24$, $p<0.001]$, as did victim annoyance $[r=0.24, p<0.001]$. 


\section{Discussion}

Moral emotions have been shown to depend critically on attributions of causal agency such as understanding who carried out a social action and why they did so (Zahn et al., 2011). Here, we have demonstrated agency and intentionality-dependent experiences of guilt, shame, annoyance and feeling "bad". We show that when taking on the role of agent, participants feel greater levels of self-blaming emotions, shame and guilt compared to annoyance, whereas when taking on the role of victim, participants feel more annoyance. Moreover, levels of shame are greater than guilt when identifying with the victim whereas participants report greater feelings of guilt compared to shame when identifying with the agent. Our results further show that when participants took on the perspective of the victim they showed significantly greater guilt, shame, annoyance and bad ratings when the harm was intentional. However, when the participant took on the perspective of the agent, ratings showed greater shame and less annoyance but no significant difference of intentionality in guilt or bad ratings.

Our results are consistent with previous findings that support the idea that different types of moral emotions such as guilt and shame can be distinguished by agency. For instance, when considering their own wrongdoings, people report more guilt than shame which may facilitate reparative actions (Schmader and Lickel, 2006). Guilt is therefore thought to be an adaptive emotion promoting moral and prosocial behaviour (Tangney et al. 1992) and thus preventing people from committing transgressions. However, when individuals consider others' wrongdoings directed at them, they feel more shame than guilt which is thought to provoke a desire to hide or leave, aimed at insulating oneself from negative evaluation (Schmader and Lickel, 2006).

In the present study we also show the effect of intentionality on moral emotions. It has long been understood that whether an action is performed intentionally or not informs our moral 
judgment of that action (Young et al., 2006). For example, embarrassing someone intentionally is morally worse than doing so accidentally. Our findings suggest that intentional harm heightens moral emotions from the perspective of the victim. Interestingly, when taking on the role of the agent, intentional harms specifically increase shame but not guilt ratings suggesting that intentionally causing harm to someone increases feelings of a more "public" emotion such as shame, perhaps from potential public exposure and disapproval. By contrast, an unintentional harm does not elicit such shameful feelings.

There was also a clear effect of gender in the present study. We observed that females had heightened feelings of guilt and shame when taking on the role of the agent. This finding is in line with previous findings suggesting that gender affects the intensity and frequency of moral affective experiences (Lutwak et al., 2001). Females are reportedly more likely to experience guilt and shame while also engaging in more prosocial/reparative behaviours than men (ElseQuest et al. 2012; Lutwak et al., 1998; Lutwak and Ferrari 1996). We found no significant gender effects for annoyance and feeling bad. When taking on the role of victim, however, females showed increased feelings of all four moral emotions suggesting clear gender differences in moral emotions regardless of intentionality. This set of findings may be useful in understanding gender differences in treatment outcomes, particularly in terms of self-blame biases and their suggested link to a vulnerability to depression (Green et al., 2013).

The findings from this study also show that personality variables such as psychoticism and neuroticism are linked to moral emotions. We observed that agent guilt, shame and feeling bad were negatively correlated with psychoticism, a personality trait typified by aggressiveness, interpersonal hostility and shares a number of core neuropsychological deficits with psychopathy (Corr, 2010). Indeed, people who display psychopathy traits are less likely to feel guilt, shame and remorse for their actions (Seara-Cardoso et al., 2012). These individuals may not lack the ability to compute moral judgments per se, but instead fail to generate the negative 
affective states that usually inhibit harmful actions towards others, such as guilt (Seara-Cardoso et al., 2016). We also observed that ratings of agent shame were significantly correlated with Neuroticism which has long been associated with heightened reactivity to negative emotional stimuli (Costa and McCrae, 1980) and brain areas implicated in neuroticism are those that have been previously associated with moral emotions (Canli et al., 2004).

Together our findings support the role of emotion in moral scenarios. This role is important in considering emotional impairments commonly found in a range of psychiatric disorders and how they influence the way individuals approach judgements about morality. For instance, individuals with psychopathy have been found to show a lack of remorse and guilt for their wrongdoings, as well as a lack of empathy for the victim (Hare et al., 1991). However, they do not appear to lack an ability to understand that an action is wrong from a societal perspective (Cima et al., 2010). By contrast, individuals with obsessive-compulsive disorder (OCD, Rachman 1993; Stewart and Shapiro 2011) often experience an exaggerated sense of guilt and responsibility, which can be largely inappropriate in the context, and is positively related to severity of symptoms (Salkovskis et al., 2000). Indeed, "feelings of guilt" is a core symptom of major depression: feelings of worthlessness or excessive or inappropriate guilt nearly every day (American Psychiatric Association, 2000). Further, delusional ideation was found to predict shameful feelings as a result of intentional harms to the victim (Savulich et al., 2018). Therefore affective responses to moral situations are likely to be impaired in a range of psychiatric disorders therefore highlighting the need for future studies in patient groups.

Whilst the present study provides novel insights into the relationship between moral emotions and personality, there are a number of limitations. First, the task assessed only two moral emotions; guilt and shame and it is unclear how other important moral emotions such as pride or embarrassment would be modulated by agency, intentionality, gender and personality in this task. Second, the data reported is from a cohort with a limited age range and a mean age of only 
26 years. Finally, static cartoons are only able to depict quite simplistic moral scenarios and therefore are unable to capture the full complexity of moral situations.

In conclusion, using this novel test of moral emotion, we have demonstrated agency and intentionality-dependent experiences of guilt, shame, annoyance and feeling bad, which are sensitive to both gender and individual differences in personality. These moral emotions are increasingly recognised as powerful determinants of decision-making and by highlighting the differential emotional experiences that help guide social behaviour, we can begin to better understand potential targets for therapeutic interventions. 


\section{References}

Abe, J.A., 2004. Shame, guilt, and personality judgment. J. Res. Pers. 38,85-104.

Alicke, M.D., 2000. Culpable control and the psychology of blame. Psychol. Bull. 126,556.

Bland, A.R., Roiser, J.P., Mehta, M.A., Schei, T., Boland, H., Campbell-Meiklejohn, D.K., Emsley, R.A., Munafo, M.R., Penton-Voak, I.S., Seara-Cardoso, A., Viding, E., Voon, V., Sahakian, B.J., Robbins, T.W., Elliott, R., 2016. EMOTICOM: A neuropsychological test battery to evaluate emotion, motivation, impulsivity, and social cognition. Front. Behav. Neurosci.10.

Buon, M., Seara-Cardoso, A., Viding, E., 2016. Why (and how) should we study the interplay between emotional arousal, Theory of Mind, and inhibitory control to understand moral cognition? Psychon. Bull. Rev. 23,1660-1680.

Canli, T., Amin, Z., Haas, B., Omura, K., Constable, R.T., 2004. A Double Dissociation Between Mood States and Personality Traits in the Anterior Cingulate. Behav. Neurosci.

Cima, M., Tonnaer, F., Hauser, M.D., 2010. Psychopaths know right from wrong but don't care. Soc. Cogn. Affect. Neurosci. 5,59-67.

Corr, P.J., 2010. The psychoticism-psychopathy continuum: A neuropsychological model of core deficits. Pers. Individ. Dif. 48,695-703.

Costa, P.T., McCrae, R.R., 1980. Influence of extraversion and neuroticism on subjective wellbeing: Happy and unhappy people. J. Pers. Soc. Psychol.

Crozier, W.R., 2014. Differentiating Shame from Embarrassment. Emot. Rev. 6,269-276.

Dentici, O.A., Pagnin, A., 1992. Moral reasoning in gifted adolescents: cognitive level and social values. Eur. J. High Abil. 3,105-114.

Derogatis, L.R., Melisaratos, N., 1983. The Brief Symptom Inventory: an introductory report. Psychol. Med. 13,595-605.

Einstein, D., Lanning, K., 1998. Shame, guilt, ego development and the five-factor model of 
personality. J. Pers. 66, 555-582.

Else-Quest, N.M., Higgins, A., Allison, C., Morton, L.C., 2012. Gender differences in self-conscious emotional experience: A meta-analysis. Psychol. Bull.

Eysenck and Eysenck, 1991. Eysenck Personality Questionnaire-Revised (EPQ-R). Hodder Stoughton, 1991.

Green, S., Ralph, M.A.L., Moll, J., Deakin, J.F.W., Zahn, R., 2012. Guilt-selective functional disconnection of anterior temporal and subgenual cortices in major depressive disorder. Arch. Gen. Psychiatry 69,1014-1021.

Greene, J.D., Sommerville, R.B., Nystrom, L.E., Darley, J.M., Cohen, J.D., 2001. An fMRI Investigation of Emotional Engagement in Moral Judgment. Science (80). 293,2105- 2108.

Haidt, J., 2003. The moral emotions. Handb. Affect. Sci. 11,852-870.

Haidt, J., Koller, S.H., Dias, M.G., 1993. Affect, culture, and morality, or is it wrong to eat your dog? J. Pers. Soc. Psychol.65,613.

Harder, D.W., Greenwald, D.F., 1999. Further validation of the shame and guilt scales of the Harder Personal Feelings Questionnaire-2. Psychol. Rep.85,271-281.

Hare, R.D., Hart, S.D., Harpur, T.J., 1991. Psychopathy and the DSM-IV criteria for antisocial personality disorder. J. Abnorm. Psychol.100,391.

Heaven, P.C.L., 1993. Personality predictors of self-reported delinquency. Pers. Individ. Dif.14,67-76.

Horberg, E.J., Oveis, C., Keltner, D., 2011. Emotions as moral amplifiers: An appraisal tendency approach to the influences of distinct emotions upon moral judgment. Emot. Rev.3,237244.

John, O.P., Donahue, E.M., Kentle, R.L., 1991. The Big Five Inventory - Versions 4a and 54. Berkeley, CA Univ. California, Berkeley, Inst. Personal. Soc. Res.

Kroll, J., Egan, E., 2004. Psychiatry, Moral Worry, and the Moral Emotions. J. Psychiatr. Pract. 10. 
Lawler, E.J., Thye, S.R., 1999. Bringing emotions into social exchange theory. Annu. Rev. Sociol. $25,217-244$.

Lutwak, N., Ferrari, J.R., 1996. Moral affect and cognitive processes: Differentiating shame from guilt among men and women. Pers. Individ. Dif. 21,891-896.

Lutwak, N., Ferrari, J.R., Cheek, J.M., 1998. Shame, guilt, and identity in men and women: the role of identity orientation and processing style in moral affects. Pers. Individ. Dif. 25, 10271036.

Lutwak, N., Panish, J.B., Ferrari, J.R., Razzino, B.E., 2001. Shame and guilt and their relationship to positive expectations and anger expressiveness. Adolescence 36, 641-653.

Malti, T., Buchmann, M., 2010. Socialization and individual antecedents of adolescents' and young adults' moral motivation. J. Youth Adolesc. 39,138-149.

Malti, T., Eisenberg, N., Kim, H., Buchmann, M., 2013. Developmental trajectories of sympathy, moral emotion attributions, and moral reasoning: The role of parental support. Soc. Dev. $22,773-793$.

Malti, T., Latzko, B., 2010. Children's moral emotions and moral cognition: Towards an integrative perspective. New Dir. Child Adolesc. Dev.2010, 1-10.

Moll, J., de Oliveira-Souza, R., Eslinger, P.J., Bramati, I.E., Mourão-Miranda, J., Andreiuolo, P.A., Pessoa, L., 2002. The neural correlates of moral sensitivity: a functional magnetic resonance imaging investigation of basic and moral emotions. J. Neurosci. 22, 2730-2736.

Moll, J., Zahn, R., de Oliveira-Souza, R., Krueger, F., Grafman, J., 2005. The neural basis of human moral cognition. Nat Rev Neurosci 6,799-809.

Moran, J.M., Young, L.L., Saxe, R., Lee, S.M., O’Young, D., Mavros, P.L., Gabrieli, J.D., 2011. Impaired theory of mind for moral judgment in high-functioning autism. Proc. Natl. Acad. Sci. 108, $2688-2692$.

Patton, J.H., Stanford, M.S., Barratt, E.S., 1995. Factor structure of the Barratt impulsiveness 
scale. J. Clin. Psychol. 51,768-774.

Peirce, J.W., 2007. PsychoPy-Psychophysics software in Python. J. Neurosci. Methods 162, 813.

Petersen, M.B., 2010. Distinct emotions, distinct domains: Anger, anxiety and perceptions of intentionality. J. Polit. 72,357-365.

Rachman, S., 1993. Obsessions, responsibility and guilt. Behav. Res. Ther. 31, 149-154.

Russell, P.S., Giner-Sorolla, R., 2013. Bodily moral disgust: What it is, how it is different from anger, and why it is an unreasoned emotion. Psychol. Bull.

Salkovskis, P.M., Wroe, A.L., Gledhill, A., Morrison, N., Forrester, E., Richards, C., Reynolds, M., Thorpe, S., 2000. Responsibility attitudes and interpretations are characteristic of obsessive compulsive disorder. Behav. Res. Ther. 38,347-372.

Savulich, G., Jeanes, H., Rossides, N., Kaur, S., Zacharia, A., Robbins, T.W., Sahakian, B.J., 2018. Moral Emotions and Social Economic Games in Paranoia. Front. Psychiatry .

Schmader, T., Lickel, B., 2006. The Approach and Avoidance Function of Guilt and Shame Emotions: Comparing Reactions to Self-Caused and Other-Caused Wrongdoing. Motiv. Emot. 30,42-55.

Seara-Cardoso, A., Neumann, C., Roiser, J., McCrory, E., Viding, E., 2012. Investigating associations between empathy, morality and psychopathic personality traits in the general population. Pers. Individ. Dif. 52,67-71.

Seara-Cardoso, A., Sebastian, C.L., McCrory, E., Foulkes, L., Buon, M., Roiser, J.P., Viding, E., 2016. Anticipation of guilt for everyday moral transgressions: The role of the anterior insula and the influence of interpersonal psychopathic traits. Sci. Rep. 6,36273.

Shacham, S., 1983. A shortened version of the Profile of Mood States. J. Pers. Assess. 47,305-306.

Sheehan, D. V, Lecrubier, Y., Sheehan, K.H., Amorim, P., Janavs, J., Weiller, E., Hergueta, T., Baker, R., Dunbar, G.C., 1998. The Mini-International Neuropsychiatric Interview (M.I.N.I.): the 
development and validation of a structured diagnostic psychiatric interview for DSM-IV and ICD-10. J Clin Psychiatry 20,22-33.

Spielberger, C.D., Gorsuch, R.L., Lushene, R.E., 1970. Manual for the state-trait anxiety inventory.

Stewart, S.E., Shapiro, L., 2011. Pathological guilt: A persistent yet overlooked treatment factor in obsessive-compulsive disorder. Ann. Clin. Psychiatry 23,63-70.

Tangney, J.P.., Wagner, P., Fletcher, C., Gramzow, R., 1992. Shamed into anger? The relation of shame and guilt to anger and self-reported aggression. J. Pers. Soc. Psychol.62.

Tangney, J.P., Fischer, K.W. (Eds.), 1995. Self-conscious emotions: The psychology of shame, guilt, embarrassment, and pride. Self-conscious Emot. Psychol. shame, guilt, embarrassment, pride.

Tangney, J.P., Stuewig, J., Hafez, L., 2011. Shame, guilt, and remorse: Implications for offender populations. J. Forens. Psychiatry Psychol. 22,706-723.

Tangney, J.P., Stuewig, J., Mashek, D.J., 2007. Moral Emotions and Moral Behavior. Annu. Rev. Psychol. 58,345-372.

Tetlock, P.E., Visser, P.S., Singh, R., Polifroni, M., Scott, A., Elson, S.B., Mazzocco, P., Rescober, P., 2007. People as intuitive prosecutors: The impact of social-control goals on attributions of responsibility. J. Exp. Soc. Psychol.43,195-209.

Valdesolo, P., DeSteno, D., 2006. Manipulations of Emotional Context Shape Moral Judgment. Psychol. Sci. 17,476-477.

Wechsler, D., 2008. Wechsler adult intelligence scale-Fourth Edition (WAIS-IV). San Antonio, TX NCS Pearson.

Whiteside, S.P., Lynam, D.R., 2003. Understanding the role of impulsivity and externalizing psychopathology in alcohol abuse: application of the UPPS impulsive behavior scale. Exp. Clin. Psychopharmacol.11,210.

Wilson, M., 2010. Constructing Measures. New York, Routledge. 
Young, L., Cushman, F., Adolphs, R., Tranel, D., Hauser, M., 2006. Does emotion mediate the effect of an action's moral status on its intentional status? Neuropsychological evidence. J. Cogn. Cult. 6,291-304.

Zahn R., De Oliveira-Souza R., J., M., 2012. Moral Emotions, Handbook of Human Affective Neurosci. Cambridge University Press.

Zahn, R., de Oliveira-Souza, R., Moll, J., 2020. Moral Motivation and the Basal Forebrain. Neurosci. Biobehav. Rev. 108,207-217.

Zahn, R., Lythe, K.E., Gethin, J.A., Green, S., Deakin, J.F.W., Workman, C., Moll, J., 2015. Negative emotions towards others are diminished in remitted major depression. Eur. Psychiatry $30,448-453$.

Zahn, R., Oliveira-Souza, R., Moll, J., 2011. Moral emotions in Handbook of Human Affective Neuroscience. Cambridge University Press. 